\title{
Nanophase Ti50at.\%Al mechanically alloyed and sintered
}

\author{
Luisa D`Angelo ${ }^{1}$, Gema Gonzalez ${ }^{2}$, Javier Ochoa ${ }^{2}$, Freddy Arenas ${ }^{3}$, Esteban Barrios ${ }^{3}$ \\ ${ }^{1}$ Departamento de Mecánica, UNEXPO, Luis Caballero Mejías, Charallave, Venezuela, \\ patina@cantv.net \\ ${ }^{2}$ Laboratorio de Ciencias e Ing. de Materiales, Instituto Venezolano de Investigaciones Científicas, \\ Caracas 1020A, Venezuela. gemagonz@ivic.ve \\ ${ }^{3}$ Instituto Universitario de Tecnología, Región Capital.
}

Mechanical Alloying is an interesting method to obtain compounds of nanometric dimensions and amorphous alloys, at room temperature. The formation of amorphous or crystalline phases of metallic compounds starting from a mixture of powders of the pure elements can be induced by interdiffusion in the solid state produced by the mechanical alloying process (MA). High energy ball milling induces a high density of lattice imperfections which affect the energy barriers leading to different reactions far from thermodynamic equilibrium, like alloying, order-disorder transformations, amorphization and other phase changes. An enhancement in the diffusion coefficients during severe plastic deformation of various elements above the thermal value has been reported [1] which can affect the reaction path that different elements choose for alloying.. For the TiAl system interesting structural transformations during milling are expected due to the different crystal structures of both metals ( $\mathrm{Ti}$-hexagonal and Al- face centered cubic) their limited solubility and the capability of crystal structure transformations with mechanical deformation $($ fcc $\leftrightarrow$ hcp).

In the present work the study of the phase transformations taking place during mechanical alloying of $\mathrm{Al}-\mathrm{Ti}$ in equiatomic concentration was carried out, considering morphology, structural evolution and formation mechanisms for the different milling periods and after sintering.

Elemental high purity $\mathrm{Al}$ and Ti powders, analytical grade, with an average particle size 12 and 29 $\mu \mathrm{m}$ respectively, were mixed in a proportion of 50 at. \%, in a WAV turbule during $1 \mathrm{~h}$ and then mechanically alloyed in nitrogen atmosphere, using a SPEX 8000, for different milling periods: 1, 3, 5, 10, 20, 30 and 50h, using stainless steel vial and balls, and a ball-to-powder weight ratio (BPR) of 8:1. The powders were characterized from each milling interval by $x$-ray diffraction in a Siemens diffractrometer D-5005, scanning electron microscopy was carried in Philips XL 30 and transmission electron microscopy was performed in a JEOL 1220 operating at $120 \mathrm{keV}$. Sintering was carried out at $2 \mathrm{GPa}$ and $700^{\circ} \mathrm{C}$ for $30 \mathrm{~min}$.

The XRD patterns of the Ti-50at\%Al for the different milling periods showed the intensity of the $\mathrm{Al}$ reflections decreasing progressively with milling until they disappear completely after 5h, indicating the formation of a Ti(Al) hexagonal solid solution with a grain size of $8 \mathrm{~nm}$. After $10 \mathrm{~h}$ amorphization takes place and by further milling a transformation to a fcc solid solution $\mathrm{Ti}(\mathrm{Al})$ is observed, with a lattice parameter of $4.11 \AA$ and a grain size of $5 \mathrm{~nm}$. TEM bright field images for the Ti-Al system are shown in Fig.1. After $5 \mathrm{~h}$ of milling a microcrystalline hep $\mathrm{Ti}(\mathrm{Al})$ solid solution was formed with a grain size in the range of $2 \mathrm{~nm}$ but some large grains of aprox. $20 \mathrm{~nm}$ were also observed (Fig. 1a) and after $50 \mathrm{~h}$ of milling a nanocrystalline Ti(Al) fcc solid solution was identified by electron diffraction (Fig. 2) with a grain size of in the range of $1.5 \mathrm{~nm}$. After sintering, the crystal structure of the milled powders was maintained and also the grain size remained nanometric. Fig. 3a shows a SEM backscattered images of the material milled for 5 and $50 \mathrm{~h}$ and sintered respectively. EBSD was carried out in the phases formed on the sintered material. 


\section{References}

[1] M.D. Baró, Yu.R. Kolobov, I.A.Ovid'ko, H.-E. Schaefer, B.B. Straumal, R.Z. Valiev, I.V. Alexandrov, M. Ivanov, K. Reimann, A.B. Reizis, S. Suriñach and A.P. Zhilyaev, Rev. Adv. Mater. Sci., 2 (2001)1-43.
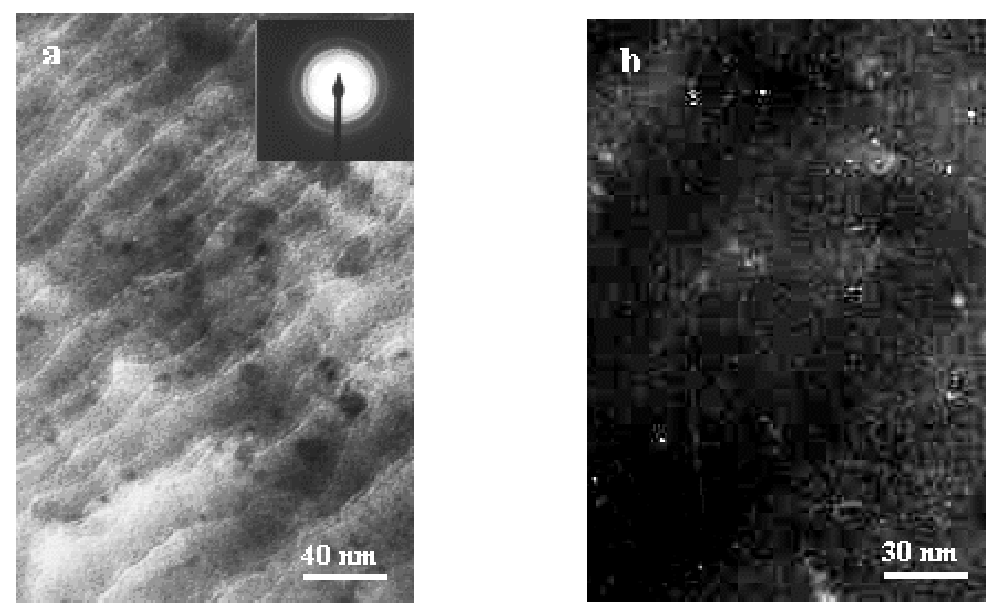

Fig. 1. TEM images of Al50at\%Ti, after $5 \mathrm{~h}$ ball milling a) Bright field, b) Dark field
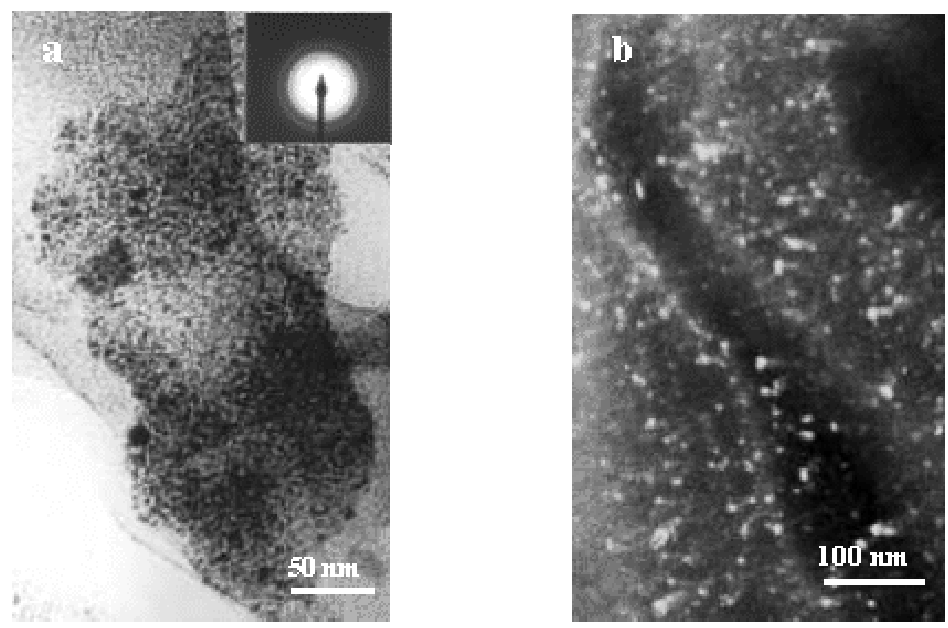

Fig 2 TEM images of Al-50at\%Ti, after 50h ball milling a) Bright field, b) Dark field
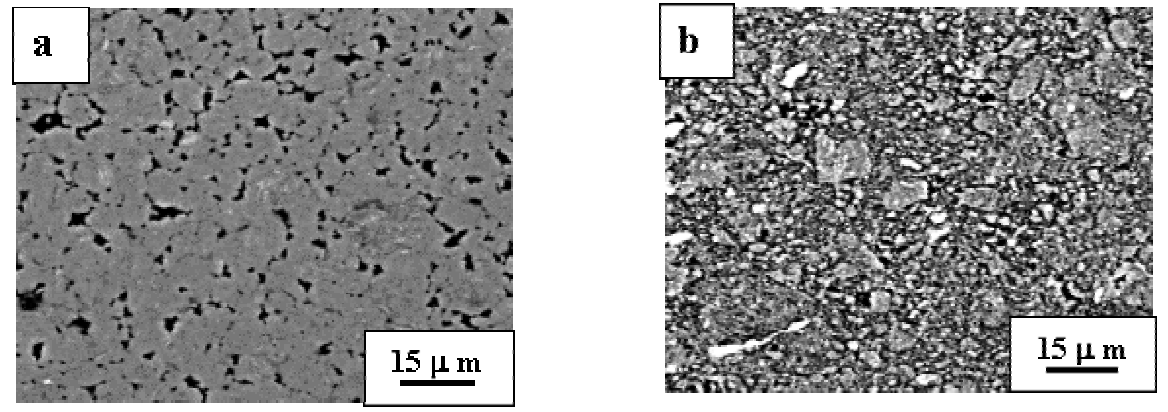

Fig. 3 SEM back scattered images of the sintered Ti 50at $\%$ Al consolidated after a) $5 \mathrm{~h}$ and $\quad$ b) 50 milling 